Stanford Genome Technology Center at Stanford University have introduced a process to detect and potentially identify single DNA molecules labeled with nanoscale gold particles. While other groups have tried to develop such screening technologies using nanopores, Karhanek and colleagues use nanopipettes combined with measurements of electrical activity. They have found that nanopipettes are faster, easier, and less expensive to fabricate than nanopores.

The nanopipettes were produced from standard quartz capillary tubes (inner diameter, $0.7 \mathrm{~mm}$; outer diameter, $1.0 \mathrm{~mm}$ ) that were pulled to a needle point with nanometer-scale openings at the point end. The pulling was accomplished with the aid of a laser-based pipette puller. The diameter of the opening of the nanopipette is $\sim 50 \mathrm{~nm}$.

The researchers attached gold particles to DNA molecules to facilitate detection. The 10-nm-diameter nanoparticles were prepared, stabilized with dipotassium bis(p-sulfonatophenyl) phenylphosphine, and bound to 24-mer oligonucleotides. Through a series of experiments, the research team focused on detecting ionic current blockade events caused by the DNA-gold particles flowing through the tip of the nanopipette. This was accomplished by placing the nanopipette, filled with a $\mathrm{KCl}$ solution and the nanoparticle-DNA colloid, into a bath containing the $\mathrm{KCl}$ solution. One $\mathrm{Ag} / \mathrm{AgCl}$ electrode was placed in the bath as a reference, and another was placed into the wide end of the nanopipette in contact with the solution. The researchers then monitored changes in current flow between the two electrodes and observed current jumps (blockades) whenever the nanoparticle or the oligonucleotide blocked ionic transport through the opening in the nanopipette.

Based on a statistical analysis of the blockade events, the researchers were able to infer structural information of the DNA-gold particles as they flowed through the sensor, including detection of the putative head and tail of the particles. They also observed that the DNA-gold particle often enters the pipette without full translocation. From the experimental data, the researchers said conditions exist for a certain energy profile with energy wells and barriers, causing a trapping and slowing of the molecules during translocation.

Karhanek and his colleagues concluded that this detection technique may lead to new versatile methods not only for the detection and identification of DNA molecules, but also for the detection of protein targets. For this purpose, the nanopipette tip could be functionalized with a target's conjugate, said Karhanek. Such experiments may shed light on different conformations of the protein-ligand complex. In more general terms, these techniques may be used to study the dynamics and interactions of various biomolecules with their environment. Not only would this be helpful for technological breakthroughs, said the researchers, but it may also help to understand fundamentals about biological processes.

MARKUS J. BUEHLER

\section{Novel Hexaferrites Show Potential for Microwave Applications}

$X$. Wang and colleagues at Tsinghua University in Beijing have synthesized $\mathrm{Ba}_{3} \mathrm{Co}_{2-x} \mathrm{Zn}_{x} \mathrm{Fe}_{24} \mathrm{O}_{41}$ hexaferrites by the citrate precursor method to obtain a single Z-type phase structure without any secondary phase, with $x=0.0,0.2,0.4,0.6$, $0.8,1.0$, and 1.2. These hexaferrites can find applications in inductors in the microwave region and ultrahigh-frequency communications, as they display high permeability, high thermal stability, and a high cutoff frequency of $\sim 2 \mathrm{GHz}$.

As reported in the February issue of the Journal of the American Ceramic Society (p.478; DOI: 10.1111/j.1551-2916.2005.00081.x), the researchers used x-ray diffraction to characterize the phase structures of the powders, measuring the specific saturation magnetization and coercive field strength of the powders. X-ray diffraction patterns revealed that the formation temperatures of Z-type phase for Zn-substituted $\mathrm{Ba}_{3} \mathrm{Co}_{2} \mathrm{Fe}_{24} \mathrm{O}_{41}$ were between $1150^{\circ} \mathrm{C}$ and $1200^{\circ} \mathrm{C}$. The substitution of $\mathrm{Co}$ by $\mathrm{Zn}$ ions at tetrahedral sites was found to result in an increase in the specific saturation magnetization. The Curie temperature, determined by thermomagnetic measurements, decreases linearly with the composition, from $410^{\circ} \mathrm{C}$ for undoped $\mathrm{Ba}_{3} \mathrm{Co}_{2} \mathrm{Fe}_{24} \mathrm{O}_{41}$ to $382^{\circ} \mathrm{C}$ for the composition with $x=1.2$.

The researchers said that $\mathrm{Ba}_{3} \mathrm{Co}_{2-x}$ $\mathrm{Zn}_{x} \mathrm{Fe}_{24} \mathrm{O}_{41}$ has high thermal stability and exhibits excellent magnetic properties; permeability rises to 9.8 for $x=1.2$ from 4.3 for the undoped $(x=0)$ samples, while the resistivity remains above $10^{9} \Omega \mathrm{cm}$ for samples sintered at $890^{\circ} \mathrm{C}$ for six hours. The researchers said that the low-temperature-sintered $\mathrm{Ba}_{3} \mathrm{Co}_{2-x} \mathrm{Zn}_{x} \mathrm{Fe}_{24} \mathrm{O}_{41}$ will be a good candidate as a ferromagnetic material for use in multilayer chip inductor and multilayer chip beads at high frequencies. VIVEK RANJAN

\section{Nitroxide-Mediated Polymerization of Styrene Demonstrated in a Continuous Tubular Reactor}

Nitroxide-mediated polymerization $(\mathrm{NMP})$, atom transfer radical polymeriza- tion, and reversible addition-fragmentation transfer polymerization are frequently used in controlled free-radical polymerization. Compared with conventional free-radical polymerization, controlled free-radical polymerization provides narrow molecular-weight polydispersity, block copolymers, and complex structures. In the February 21 issue of Macromolecular Rapid Communications (p. 221; DOI: 10.1002/marc.200400531), T.E. Enright and B. Keoshkerian of the Xerox Research Centre of Canada and M.F. Cunningham of Queen's University, Canada, reported polystyrene preparation by a nitroxidemediated mini-emulsion polymerization in a continuous tubular reactor. They used this method not only to simplify the polymer's synthesis with controlled microstructure, but also to provide better temperature and pressure control during the reaction. In addition, said Cunningham, "industry has expressed concerns over having to pressurize a batch (tank) reactor to run NMP in miniemulsion, as it is not a standard practice, and the existing equipment is not wellsuited for pressurized operation. However, tubular reactors can easily accommodate the modest pressures required $(\sim 300 \mathrm{kPa})$ and would be less expensive than tank reactors."

In the NMP of styrene, bulk prepolymerization was performed in batch by mixing styrene with benzyl peroxide and 2,2,6,6tetramethyl-1-piperidinyloxy (TEMPO) in a 21 stainless-steel reactor. TEMPO was used as the nitroxide-mediating agent. After the reactor was heated up to $135^{\circ} \mathrm{C}$ and cooled to room temperature, the monomerpolymer (a low-conversion polystyrene oligomer) mixture was dispersed in the aqueous phase, which was a sodium dodecylbenzenesulfonate deionized water solution. Then the mixture went through a homogenizer under a pressure of 400-600 bar, and the mini-emulsion latex was formed. Upon filling with the latex at the desired feed rate, this continuous reaction was performed in a $167 \mathrm{~m}$ stainless-steel tube coil in a $135^{\circ} \mathrm{C}$ oil bath. A simultaneous batch reaction was also done for comparison.

In either continuous or batch reaction, a stable latex was formed with a volume mean particle size of $164 \pm 61 \mathrm{~nm}$ in the batch reactor and $170 \pm 59 \mathrm{~nm}$ in the continuous reactor. Upon calculation, the coagulum left in both reactors was less than $0.5 \mathrm{wt} \%$ of the overall polymer. Both reactions showed very similar kinetic behavior such as the reaction conversion and rate. The polymers were characterized by gel permeation chromatography. For the polymer obtained from the tubu- 
lar reactor, its number-average molecular weight increased linearly with the conversion; and its polydispersity index was narrow $(<1.5)$, indicating the controlled nature of the polymerization mechanism. In addition, the final product still maintained living characteristics, as shown by its narrow polydispersity and the chain extension experiments. The polymer from the batch reactor showed comparable results.

LuCY Yue Hu

\section{Review Articles...}

Applied Mechanics Reviews 57 (5) (September 2004) contains T.-Y. Fan and Y.-W. Mai, "Elasticity Theory, Fracture Mechanics, and Some Relevant Thermal Properties of Quasi-Crystalline Materials," p. 325; W.L Oberkampf, T.G. Trucano, and C. Hirsch, "Verification, Validation, and Predictive Capability in Computational Engineering and Physics," p. 345; and G.B. Sinclair, "Stress Singularities in Classical Elasticity-II: Asymptotic Identification," p. 385.

Journal of Applied Physics 97 (4) (February 15, 2005) contains A.V. Melechko, V.I. Merkulov, T.E. McKnight, M.A. Guillorn, K.L. Klein, D.H. Lowndes, and M.L. Simpson, "Vertically Aligned Carbon Nanofibers and Related Structures: Controlled Synthesis and Directed Assembly," 041301.

Low Temperature Physics 31 (1) (January 2005) contains V.I. Kut'ko, "Dynamics of Layered Jahn-Teller Crystals of RareEarth Compounds (Review)," p. 1.

Thin Solid Films 476 (1) (April 1, 2005) contains S. Veprek, M.G.J. VeprekHeijman, P. Karvankova, and J. Prochazka, "Different Approaches to Superhard Coatings and Nanocomposites," p. 1.

Thin Solid Films 476 (2) (April 8, 2005) contains S. Berg and T. Nyberg, "Fundamental Understanding and Modeling of Reactive Sputtering Processes," p. 215.

\section{....and Special Issues/Sections}

Applied Acoustics 66 (6) (June 2005) is a special issue on Innovative Applications of Materials for Acoustic Purposes.

Applied Mechanics Reviews 57 (6) (November 2004) is a special issue on Nonlinear Vibrations of Suspended Cables, containing G. Rega, "Nonlinear Vibrations of Suspended Cables-Part I: Modeling and Analysis," p. 443; G. Rega, "Nonlinear Vibrations of Suspended Cables-Part II: Deterministic Phenomena," p. 479; and R.A. Ibrahim, "Nonlinear Vibrations of Suspended CablesPart III: Random Excitation and Interaction with Fluid Flow," p. 515.

IBM Journal of Research and Development 49 (1) (2005) contains a special section on Electrochemical Technology in Microelectronics.

IEEE Transactions on Advanced Packaging 28 (1) (February 2005) contains a special section with selected papers from the 2003 Electrical Performance of Electronic Packaging Conference.

IEEE Transactions on Industrial Elec- tronics 52 (1) (February 2005) contains a special section on Modern Rectifiers.

IEEE Transactions on Magnetics 41 (2) (February 2005) contains selected papers from the 15th Annual Magnetic Recording Conference (TMRC 2004), held in Boulder, Colo., August 11-13, 2004; selected papers from the Third North American Perpendicular Magnetic Recording Conference (NAPMRC 2004), held in Boulder, Colo., on August 10, 2004; selected papers from the AsiaPacific Magnetic Recording Conference (APMRC 2004), held in Seoul, Korea, August 16-19, 2004; and selected papers from the third Asia-Pacific Data Storage Conference (APDSC 2004), held in Taiwan September 27-29, 2004.

IEEE Transactions on Microwave Theory and Techniques 53 (2) (February 2005) contains a special section with three papers from the 15th International Conference on Microwaves, Radar, and Microwave Communications (MIKON 2004), held in Warsaw, Poland, May 17-19, 2004; and a special section containing expanded papers from the 2004 Radio Frequency Integrated Circuits (RFIC) Symposium, held in Fort Worth, Texas, June 6-8, 2004.

IEEE Transactions on Nanotechnology 4 (1) (January 2005) is a special issue containing papers from the 2004 IEEE Nanotechnology Council (NTC) Quantum Device Technology Workshop, held in Potsdam, New York, May 17-21, 2004.

IEEE Transactions on Plasma Science 33 (1) (February 2005) is a special issue containing the plenary and invited papers from the 31st International Conference on Plasma Science (ICOPS), held in Baltimore, Md., in June 2003.

IEEE Transactions on Semiconductor Manufacturing 18 (1) (February 2005) is a special issue on Materials-Related Manufacturing Issues in the Nanochip Era.

Infrared Physics \& Technology 46 (1-2) (December 2004) is a special issue containing papers from the Workshop on Advanced Infrared Technology and Application, held in Pisa, Italy, September 9-11, 2003.

Journal of Biomedical Optics 10 (1) (January 2005) contains a special section on Optics in Neuroscience.

Journal of Electronic Packaging 126 (4) (December 2004) is a special issue containing selected papers from the symposium on Thermal Management of Electronic Systems, held at the ASME IMECE in Washington, D.C., in No- vember 2003. Other selected papers from this symposium are published in the Journal of Heat Transfer 127 (1) (January 2005).

Journal of Engineering Materials and Technology 127 (1) (January 2005) contains a special section bringing together selected papers from the ASME Symposium on the Fatigue of Advanced Materials, held as part of the ASME Winter Annual Meeting in New Orleans, La., in November 2002.

Journal of Infrastructure Systems 11 (1) (March 2005) is a special issue on Sustainability of Transportation and Other Infrastructure Systems.

Journal of Lightwave Technology 23 (1) (January 2005) is a special issue containing papers from the Optical Fiber Communications (OFC) Conference, held in Los Angeles, Calif., in March 2004.

Journal of Microlithography, Microfabrication, and Microsystems 4 (1) (January 2005) contains a special section on NextGeneration Lithography.

Journal of Physics and Chemistry of Solids 66 (24) (February-April 2005) is a special issue containing papers from the proceedings of the 11th International Conference on High Temperature Materials Chemistry (HTMC-XI), held in Tokyo, Japan, May 19-23, 2003.

Optical Materials 27 (5) (February 2005) is a special issue containing papers on $\mathrm{Si}-$ Based Photonics: Towards True Monolithic Integration.

Physics of Fluids 17 (3) (March 2005) contains a special section on Biofluid Mechanics.

Physics of the Solid State 47 (1) (January 2005) contains a special section with papers from the Proceedings of the conference Nanophotonics 2004.

Powder Diffraction 19 (4) (December 2004) contains a special section on selected papers from the 8th National Chinese Symposium on X-Ray Diffraction, held in Nanning, China, October 29-November 1, 2003.

Thin Solid Films 475 (1-2) (March 22, 2005) is a special issue containing papers from the 4th Asian-European International Conference on Plasma Surface Engineering 2003, held in Jeju City, Korea, September 28-October 3, 2003.

Vacuum 77 (4) (March 11, 2005) is a special issue containing selected papers from the 7th International Conference on Electron Beam Technologies, held in Varna, Bulgaria, on June 2-5, 2003. 